\title{
CHARACTERIZATION AND MODELLING OF NI BASED SUPERALLOY MATERIALS WITH A DUAL LAYERED MCRALY COATING SYSTEM
}

\author{
Y. Liu, M.S.A. Karunaratne, M.A.E. Jepson and R.C. Thomson \\ Department of Materials, Loughborough University, Loughborough, LE11 3TU, UK
}

Keywords: Ni-based superalloys, Diffusion modelling, Multi-layer coatings

\begin{abstract}
Multilayered MCrAlY type coatings have the potential to be optimised to protect superalloy components against both corrosion and oxidation simultaneously. In this paper, a dual layered coating ( $\mathrm{NiCr}(\mathrm{Co}) \mathrm{AlY}$ on top of a NiCoCrAlY coating) has been aged and the microstructural evolution has been observed and quantified using various electron microscopy based techniques. In addition, the microstructural evolution of the coating has been modelled using a diffusion based model capable of predicting the ageing of multilayer coatings. It is demonstrated that the model is reasonably accurate in predicting both the phase and chemical distributions through the coating system during ageing, and therefore has the potential to be used as a design tool for the improvement of future layered coating systems.
\end{abstract}

\section{Introduction}

Turbine blades increasingly rely on the performance of coating systems for high temperature degradation protection. MCrAlY coatings (where $\mathrm{M}$ is typically $\mathrm{Ni}$ and/or Co) are widely used to provide oxidation and high temperature corrosion resistance for $\mathrm{Ni}$ based superalloy components. The protection is obtained through the formation of dense and adherent oxide scales, which are normally rich in aluminium oxides.

Traditionally, single layer MCrAlY coatings have been directly used on superalloy substrates for corrosion/oxidation protection or increasingly, as a bond coat between thermal barrier coatings (TBCs) and substrates. It has recently been shown that compositionally graded and/or multi-layered coating systems [13] have the potential to provide much improved oxidation and corrosion resistance over single layer coatings for superalloy components used in turbine engines operated under multiple corrosion regimes. Dual layer coatings with two carefully selected MCrAlY layers replacing the single layer of the MCrAlY, however, could utilise established production routines and are a natural extension of current coating systems. Little work has been reported to date on the topic of dual layer MCrAlY type coatings, and therefore this paper investigates the microstructural evolution of a dual layered MCrAlY type coating using a combination of experimental and modelling techniques.

\section{Model Formulation}

The microstructure evolution in the dual layer coating system has been simulated using a computer model [4] based on a 1-D multicomponent finite-difference (F-D) diffusion calculation which also incorporates oxide scale formation and equilibrium thermodynamics, to predict multiple phases present at locations across the coating system and substrate as a function of temperature and time. The experimentally observed microstructures with their constituent phases and the measured elemental concentration profiles have been compared directly with the simulation output.

\section{Diffusion Model}

Due to the planar nature of interfaces between layers, and between the layers and the substrate, diffusion occurring in a typical multilayer coating system can be approximated by a one-dimensional model. The diffusion of elements within the coating/substrate system is hence modelled using the 1-D multicomponent representation of the Fick-Onsager Law [5,6] given by:

$$
\frac{\partial C_{i}}{\partial t}=\sum_{j=1}^{n-1}\left\{\widetilde{D}_{i j}^{n} \frac{\partial^{2} C_{j}}{\partial x^{2}}+\left(\sum_{k=1}^{n-1} \frac{\partial}{\partial C_{k}} \widetilde{D}_{i k}^{n} \frac{\partial C_{k}}{\partial x}\right) \frac{\partial C_{j}}{\partial x}\right\}
$$

where $x$ and $t$ are distance and time, respectively; $i, j$ and $k$ are chemical elements and the interdiffusion coefficient matrix $\widetilde{D}_{i j}^{n}$ is expressed in relation to a solvent $n$, which for the present system is $\mathrm{Ni}$, and $C_{i}$ is the concentration of $i$.

\section{$\underline{\text { Diffusion coefficients }}$}

Interdiffusion coefficients in the $\mathrm{Ni}$-fcc phase are obtained from several published sources: the temperature and concentration dependent binary interdiffusion data are available for elements Co [7], Mo [8], Ti [9], Re, W and Ta [10], and concentration independent data are incorporated for $\mathrm{Al}$ [11] and $\mathrm{Cr}$ [12]. For the $\gamma^{\prime}$ phase, temperature dependent diffusion coefficients of $\mathrm{Al}$ [13], $\mathrm{Ti}$ [14] and $\mathrm{Co}$ and $\mathrm{Cr}$ [15] are used. For the $\beta$ phase, concentration and temperature dependent diffusion coefficients of $\mathrm{Al}$ provided in [16] are used. Since diffusion data are unavailable for elements within the TCP phases and, since diffusivity is expected to be slow in ordered TCP phases and the BCC $\alpha-\mathrm{Cr}$ phase, the diffusion coefficient is assumed to be a fraction (5\%) of that in the FCC-Ni phase. The concentration dependence of all diffusion coefficients is modelled by fitting third degree polynomials to published data, and their temperature dependence is modelled by assuming the Arrhenius behaviour. Full details of the modelling process and fitted parameters are given in [17] and hence not reported here. For each node in the F-D grid, an effective diffusion coefficient for each element is calculated by taking a volume weighted average of concentration dependent diffusion coefficients in each phase.

\section{Oxidation Model}

For oxidation, a scheme proposed by Meier et al. for a NiCoCrAlY based bond coat is used [18] which gives the thickness, $\delta$, of the oxide scale as:

$$
\delta=\left[\exp \left\{Q\left(\frac{1}{T_{0}}-\frac{1}{T}\right)\right\} t\right]^{n}
$$


where $Q, T_{0}$ and $n$ are constants equal to $27777.4,2423.7 \mathrm{~K}$ and 0.332 , respectively; $T$ is the temperature in $\mathrm{K}$, and $t$ is the time in seconds. The current model assumes that only $\mathrm{Al}$ is oxidized at the coating surface, and the diffusion of elements within the oxide is not modelled explicitly.

\section{Thermodynamic model}

The thermodynamic equilibrium calculations at each node have been performed using the Application Program Interface (API) [19] of MTDATA [20]. The MTDATA program consists of a numerical technique for the minimization of Gibbs free energy of a chemical system, and here it is used in conjunction with a thermodynamic database for Ni-based superalloys, Ni-DATA [ 21 , 22]. The code calls the API at each time-step, with the concentration at each node sequentially. The API in turn returns a description of the fractional constitution and composition of equilibrium phases which are likely to be present at each node. The API calls are computationally expensive because of the large number of elements and alloy phases involved. Because a large number of such calculations have to be performed, the simulations have been carried out in parallel by partitioning the spatial nodes among multiple processors using a high performance computing facility (HPC) at Loughborough University.

\section{Grid Scheme}

In the model, the differential terms in Equation (1) are replaced by their F-D equivalents as detailed in [17]. The explicit solution scheme is used to solve for concentrations of all elements. To make calculations more efficient, initially, a number of F-D grid zones are located only in areas where concentration gradients are steepest, i.e. (a) near the oxidation interface, (b) between coating layers and (c) near the coating-layer/substrate boundary. Regions further away are assumed to have zero concentration gradients and hence semi-infinite boundary conditions are imposed at either end of each grid zone, except at the oxidation interface. As the concentration fields extend with time, the F-D grid zones are expanded dynamically [17] while the oxidation interface was treated as a moving phase boundary, using a published scheme [23]. The boundary condition at the oxidation interface is given by the rate of $\mathrm{Al}$ consumption derived from Equation (2). The expansion of grid zones continues until the neighbouring zones overlap (soft impingement), at which point the zones are merged to form a single zone.

\section{Experimental Methods}

\section{Materials and Heat Treatment}

The experimental samples used in this work comprised a dual layer bond coating, $\mathrm{NiCr}(\mathrm{Co}) \mathrm{AlY}$ (nominal thickness $50 \mu \mathrm{m})+$ NiCoCrAlY (nominal thickness $125 \mu \mathrm{m}$ ), overlaid on a conventionally cast superalloy substrate (IN738). They were additionally protected by an 8 wt.\% yttria stabilised zirconia (YSZ) thermal barrier coating (TBC). It was noted that the outer NiCrAlY layer was found to contain a significant amount of the element Co after spraying, and is therefore referred to as a $\mathrm{NiCr}(\mathrm{Co}) \mathrm{AlY}$ layer in this paper. The chemical compositions of the inner and outer coating layers measured at their respective centres away from any effects of interdiffusion, and the nominal composition of the IN-738 substrate are given in Table 1.
Table 1. Measured chemical compositions at the centres of the two coating layers and the nominal chemical composition of the substrate (wt.\%)

\begin{tabular}{|c|r|r|r|}
\hline & NiCr(Co)AIY & NiCoCrAIY & \multicolumn{1}{|c|}{ IN-738 } \\
\hline Co & 10.00 & 33.00 & 8.26 \\
\hline $\mathbf{C r}$ & 22.00 & 21.00 & 15.98 \\
\hline $\mathbf{A l}$ & 10.00 & 8.00 & 3.36 \\
\hline $\mathbf{Y}$ & 1.00 & 0.50 & 0.00 \\
\hline $\mathbf{M o}$ & 0.00 & 0.00 & 1.76 \\
\hline $\mathbf{N b}$ & 0.00 & 0.00 & 0.80 \\
\hline $\mathbf{T a}$ & 0.00 & 0.00 & 1.67 \\
\hline $\mathbf{T i}$ & 0.00 & 0.00 & 3.35 \\
\hline $\mathbf{W}$ & 0.00 & 0.00 & 2.67 \\
\hline $\mathbf{N i}$ & 57.00 & 37.50 & Balance \\
\hline
\end{tabular}

The thicknesses of the coatings were found to vary along the TBC / MCrAlY interface. In the as-received (AR) state, the samples had received a standard pre-service, post-coating heat treatment (PHT) at $1120^{\circ} \mathrm{C}$ for $2 \mathrm{~h}$, followed by ageing at $845^{\circ} \mathrm{C}$ for $24 \mathrm{~h}$ in vacuum. These samples were then isothermally aged at $1000^{\circ} \mathrm{C}$ for a range of times up to $3000 \mathrm{~h}$ in ambient air.

\section{Sample Preparation}

Experimental test coupons were cut using a Struers Accutom-5 saw with a water cooled $\mathrm{Al}_{2} \mathrm{O}_{3}$ cutting disk. The samples were then mounted using edge-retaining conductive Bakelite. A series of grinding stages with water lubrication using 200, 600, 1200 grit papers were then carried out, followed by separate polishing stages with standard cloths and diamond suspensions, down to a 1 $\mu \mathrm{m}$ finish. Samples were then polished with $0.04 \mu \mathrm{m}$ colloidal silica suspension for 4 minutes to remove the remaining fine scratches and irregularities left from prior polishing processes. Etching of the samples was carried out using electrolytic etching in $10 \%$ orthophosphoric acid in water, with an applied potential difference of $10 \mathrm{~V}$ for a total time of $\sim 20$ seconds.

\section{Scanning Electron Microscopy and Focused Ion Beam} Microscopy

A Leo 1530 VP Field Emission Gun Scanning Electron Microscope (FEGSEM), in conjunction with Energy-Dispersive $\mathrm{x}$-ray Spectroscopy (EDS) was used for imaging and chemical mapping, operating at an accelerating voltage of $20 \mathrm{kV}$. The system was operated using backscattered and secondary electron imaging modes. The FEGSEM was operated at a working distance of approximately $10 \mathrm{~mm}$ throughout. An FEI Nova Nanolab 600 dual beam, Focussed Ion Beam / FEGSEM (FIBSEM) was used in this project for a variety of functions including Electron Backscatter Diffraction (EBSD), EDS elemental analysis, and site-specific sample preparation for Transmission Electron Microscopy (TEM). The quantification of element diffusion throughout the coating layer was carried out using an EDS scanning technique. The lines were made up of a series of rectangular regions equally spaced from the substrate to the surface of the coating. Each analytical region was a $10 \mu \mathrm{m} \times 200$ $\mu \mathrm{m}$ rectangular box. The average concentration for each element within each box was then taken to form a distribution profile. The 
use of this technique avoids the production of overly scattered EDS line profiles which can be caused by sampling many different phases present within the coating system.

The quantification of the $\beta$ phase was carried out by optimising the contrast of the $\beta$ phase particles on the FEGSEM image collected, then by careful thresholding and quantification of the phase area fraction using the image analysis software, ImageJ.

\section{Experimental Results}

An overview of the as-received and isothermally aged samples is given in Figure 1. The two distinct inner and outer coating layers are easily distinguishable and different phases within each layer can be seen as marked in Figure 1(a). It is observed that the individual phase 'particles' appear to coarsen significantly with increased ageing. In addition, the thermally grown oxide (TGO) thickens with increasing ageing time. The oxide has been identified using EDS as primarily alumina, with some chromia also present, particularly in the early stages of ageing.

According to the different phase contrast observed in the asreceived and $100 \mathrm{~h}$ aged samples, there are three different particle types indicated in Figure 1(b); bright regions (B), grey regions $(\mathrm{G})$ and dark regions (D) in the outer layer and bright regions and grey regions in the inner layer. In the $1000 \mathrm{~h}$ aged sample, the grey region in the inner layer had almost disappeared. In the $3000 \mathrm{~h}$
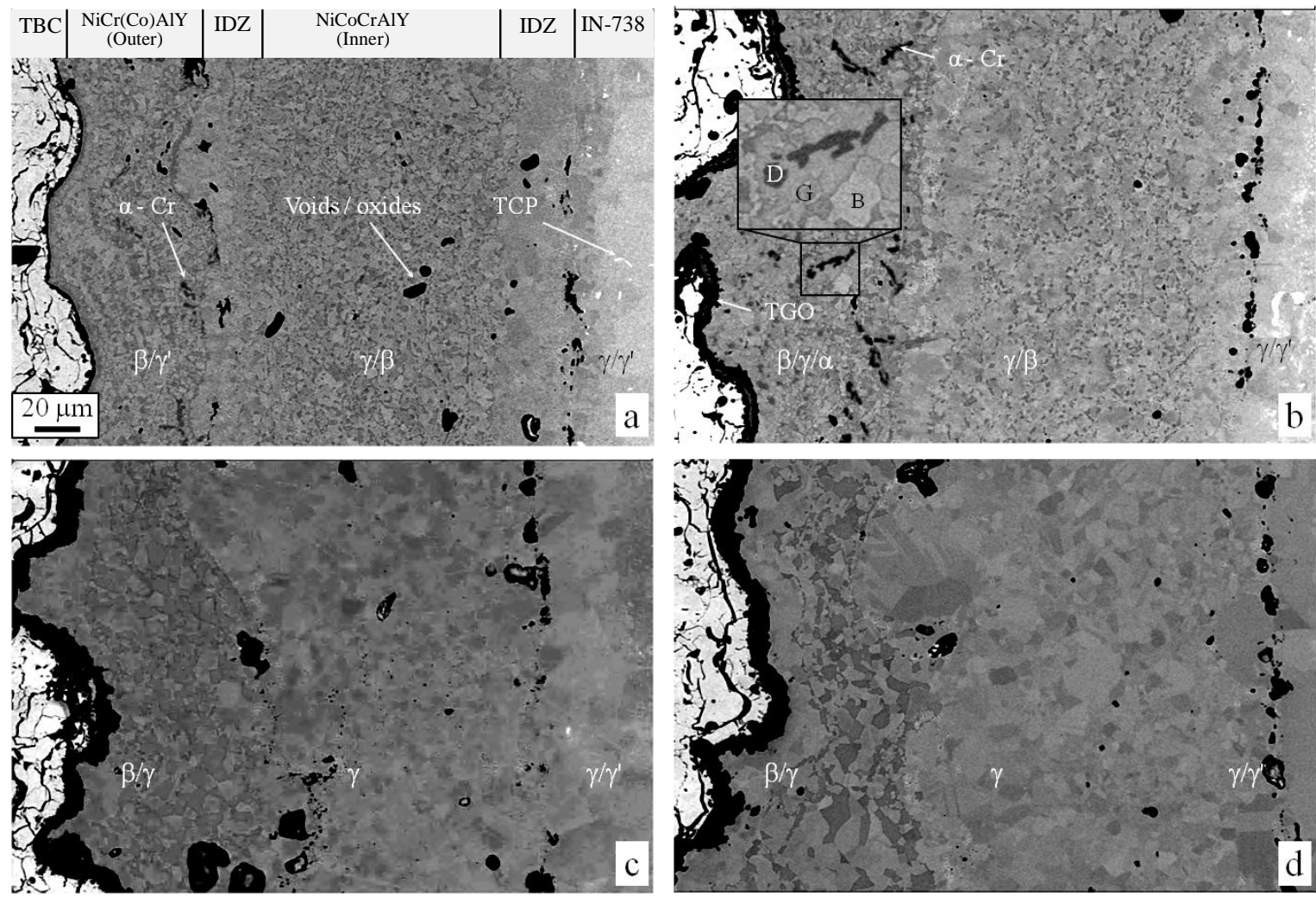

Figure 1. Back scattered electron images of (a) as received (AR) dual layer coating, (b) after ageing at $1000^{\circ} \mathrm{C}$ for $100 \mathrm{~h}$, (c) after ageing at $1000^{\circ} \mathrm{C}$ for $1000 \mathrm{~h}$ and (d) after ageing at $1000^{\circ} \mathrm{C}$ for $3000 \mathrm{~h}$. aged sample, the bright region in the inner layer had disappeared completely; however, the bright region in the outer layer still remained.

To identify these different phases, EDS analyses of SEM samples and TEM analyses based on site-specific samples made using FIB

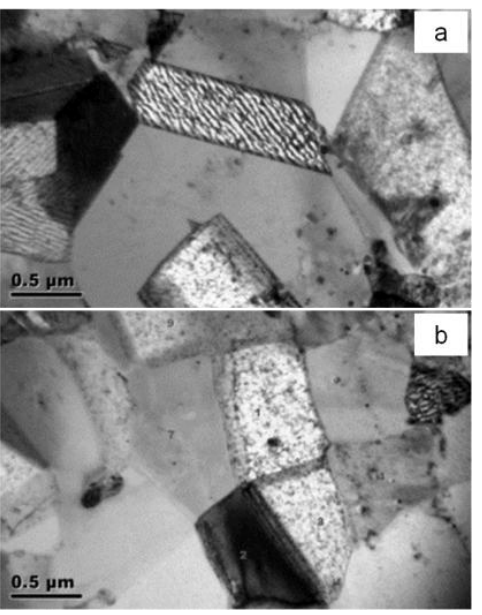

Figure 2. Bright field TEM images of (a) outer layer of the AR sample and (b) inner layer of the $100 \mathrm{~h}$ aged sample, at $1000^{\circ} \mathrm{C}$

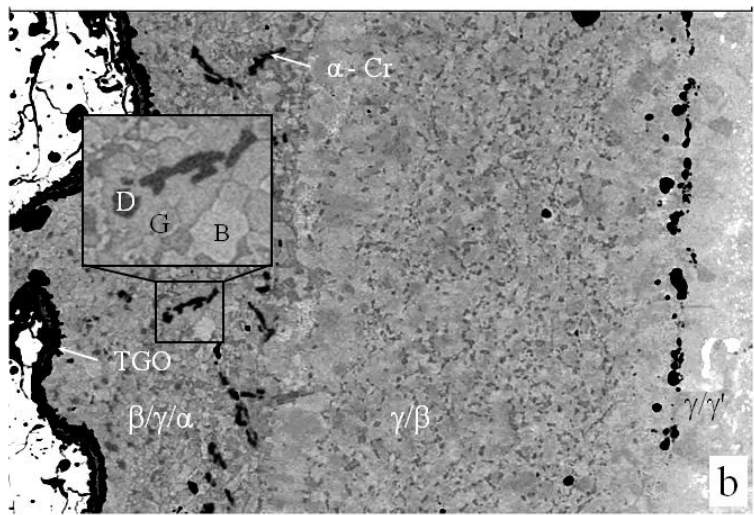


were compared with the theoretical chemical compositions of a number of phases predicted by the model. Figure 2 shows that within each TEM sample, grains with different contrast were observed. In order to identify the phases present, the grains were analysed in the TEM using EDS, and the results compared with the EDS measurements from the FEGSEM together with the calculated phase compositions provided by the simulation model. The comparison is summarised in Table 2 .

Table 2. Comparison of elemental concentration of regions in (a) AR sample outer layer and (b) 100h aged sample inner layer.

\begin{tabular}{|l|l|l|l|l|}
\hline (a) at.\% & & Model & TEM & SEM \\
\hline \multirow{3}{*}{$\begin{array}{l}\gamma^{\prime} \text { (bright } \\
\text { region) }\end{array}$} & $\mathrm{Ni}$ & 62.5 & $63 \pm 0.3$ & $64 \pm 0.8$ \\
\cline { 2 - 5 } & $\mathrm{Co}$ & 7.5 & $7 \pm 0.4$ & $6 \pm 0.3$ \\
\cline { 2 - 5 } & $\mathrm{Cr}$ & 9 & $9 \pm 0.2$ & $10 \pm 0.2$ \\
\cline { 2 - 5 } & $\mathrm{Al}$ & 21 & $21 \pm 0.5$ & $20 \pm 0.5$ \\
\hline \multirow{3}{*}{$\begin{array}{l}\alpha-\mathrm{Cr} \\
\text { (dark } \\
\text { region) }\end{array}$} & $\mathrm{Ni}$ & 1 & $2 \pm 0.3$ & $4 \pm 1.3$ \\
\cline { 2 - 5 } & $\mathrm{Co}$ & 7 & $2 \pm 0.3$ & $2 \pm 0.7$ \\
\cline { 2 - 5 } & $\mathrm{Cr}$ & 91 & $95 \pm 2$ & $92 \pm 2.9$ \\
\cline { 2 - 5 } & $\mathrm{Al}$ & 1 & $1 \pm 0.5$ & $1 \pm 1$ \\
\hline \multirow{3}{*}{$\begin{array}{l}\text { (grey } \\
\text { region) }\end{array}$} & $\mathrm{Ni}$ & 54 & $53.5 \pm 0.8$ & $55 \pm 1.4$ \\
\cline { 2 - 5 } & $\mathrm{Co}$ & 8 & $8 \pm 0.3$ & $5 \pm 0.9$ \\
\cline { 2 - 5 } & $\mathrm{Cr}$ & 4 & $5 \pm 0.2$ & $7 \pm 0.8$ \\
\cline { 2 - 5 } & $\mathrm{Al}$ & 34 & $33.5 \pm 0.7$ & $32 \pm 0.3$ \\
\hline
\end{tabular}

\begin{tabular}{|l|l|l|l|l|}
\hline (b) at.\% & & Model & TEM & SEM \\
\hline $\begin{array}{l}\gamma \\
\text { region } \\
\text { regight }\end{array}$ & $\mathrm{Ni}$ & 34 & $35 \pm 0.3$ & $41 \pm 0.2$ \\
\cline { 2 - 5 } & $\mathrm{Co}$ & 32 & $31 \pm 0.2$ & $27 \pm 0.3$ \\
\cline { 2 - 5 } & $\mathrm{Cr}$ & 25 & $25 \pm 0.4$ & $23 \pm 0.4$ \\
\cline { 2 - 5 } & $\mathrm{Al}$ & 9 & $9 \pm 0.2$ & $9 \pm 0.4$ \\
\hline \multirow{3}{*}{$\begin{array}{l}\beta \text { (grey } \\
\text { region) }\end{array}$} & $\mathrm{Ni}$ & 43 & $47 \pm 0.9$ & $50.5 \pm 0.7$ \\
\cline { 2 - 5 } & $\mathrm{Co}$ & 20 & $14 \pm 0.7$ & $13 \pm 0.5$ \\
\cline { 2 - 5 } & $\mathrm{Cr}$ & 6 & $4.5 \pm 0.4$ & $6.5 \pm 0.3$ \\
\cline { 2 - 5 } & $\mathrm{Al}$ & 31 & $34.5 \pm 0.2$ & $30 \pm 0.7$ \\
\hline
\end{tabular}

Table 2 shows that good agreement for the phase chemical compositions was observed between the model prediction and experimental results from both TEM and SEM measurements. All of the different regions appearing in each sample were analysed using the same method. A summary of the phases identified in each sample is given in Table 3 and indicated in Figure 1.

Table 3 shows that initially, the as-received sample consists of $\gamma^{\prime}$ (bright region), $\beta$ (grey region), and $\alpha-\mathrm{Cr}$ (dark region) in the outer layer, and $\gamma$ (bright region) and $\beta$ (grey region) in the inner layer. After $100 \mathrm{~h}$ of ageing, $\gamma^{\prime}$ in the outer layer changed into $\gamma$ and the rest of the phases remained the same. After 1000h, $\alpha-\mathrm{Cr}$ phase disappeared in the outer layer and only a small amount of $\beta$ phase remained in the inner layer. After $3000 \mathrm{~h}$, the $\beta$ phase was not observed in the inner layer.
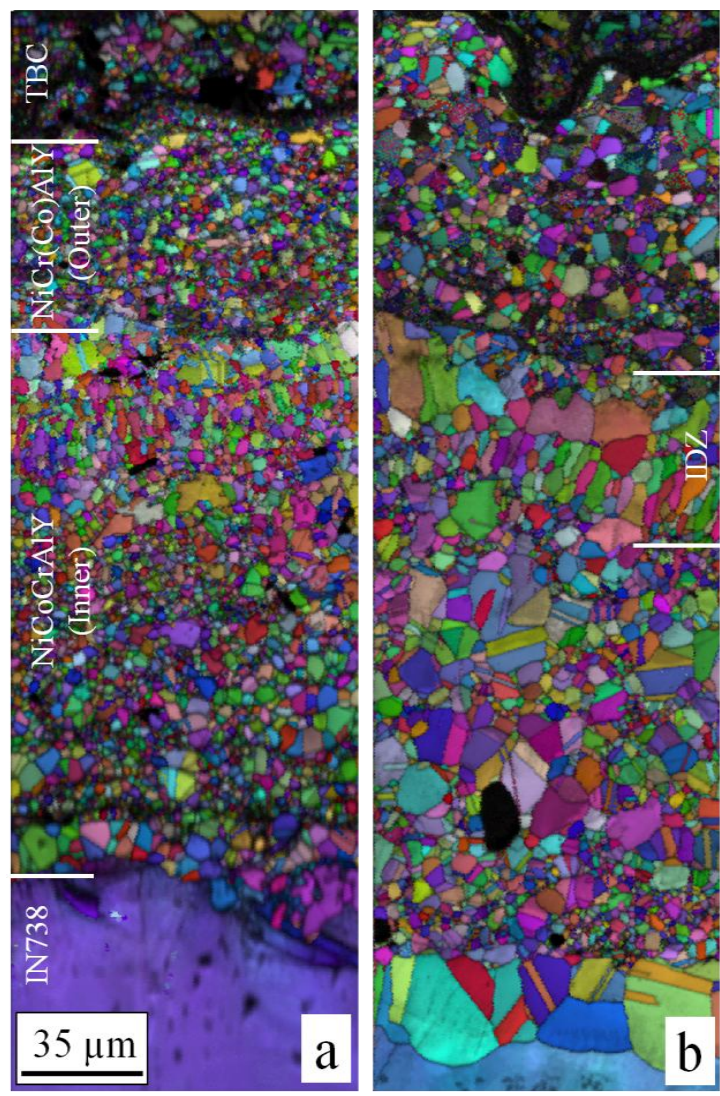

Figure 3. EBSD maps of (a) as-received sample; (b) $1000 \mathrm{~h}$ aged sample at $1000^{\circ} \mathrm{C}$.

In addition, the grain structure across the coating system was revealed using EBSD. Figure 3 shows that the grain size in both coating layers coarsened with ageing, especially within the inner NiCoCrAlY layer. Significant grain growth was observed in to the substrate at the interface between the substrate and the inner coating layer.

Table 3. Summary of phases confirmed by experiments

\begin{tabular}{|c|c|c|c|c|c|c|c|c|}
\hline & \multicolumn{2}{|c|}{ AR } & \multicolumn{2}{c|}{$100 \mathrm{~h}$} & \multicolumn{2}{c|}{$1000 \mathrm{~h}$} & \multicolumn{2}{c|}{$3000 \mathrm{~h}$} \\
\hline & $\begin{array}{c}\text { Outer } \\
\text { layer }\end{array}$ & $\begin{array}{c}\text { Inner } \\
\text { layer }\end{array}$ & $\begin{array}{c}\text { Outer } \\
\text { layer }\end{array}$ & $\begin{array}{c}\text { Inner } \\
\text { layer }\end{array}$ & $\begin{array}{c}\text { Outer } \\
\text { layer }\end{array}$ & $\begin{array}{c}\text { Inner } \\
\text { layer }\end{array}$ & $\begin{array}{c}\text { Outer } \\
\text { layer }\end{array}$ & $\begin{array}{c}\text { Inner } \\
\text { layer }\end{array}$ \\
\hline$\gamma$ & - & $\checkmark$ & $\checkmark$ & $\checkmark$ & $\checkmark$ & $\checkmark$ & $\checkmark$ & $\checkmark$ \\
\hline$\gamma^{\prime}$ & $\checkmark$ & - & - & - & - & - & - & - \\
\hline$\beta$ & $\checkmark$ & $\checkmark$ & $\checkmark$ & $\checkmark$ & $\checkmark$ & $\checkmark$ & $\checkmark$ & - \\
\hline$\alpha-\mathrm{Cr}$ & $\checkmark$ & - & $\checkmark$ & - & - & - & - & - \\
\hline
\end{tabular}

It was observed that in the interdiffusion zone (IDZ) between the two coating layers, two bands of elongated grains formed after $1000 \mathrm{~h}$. The first band, which was close to the inner layer, consisted of larger grains. Between the inner layer and this band, was a second band of more elongated grains. The direction of elongation is approximately perpendicular to the coating interface. 

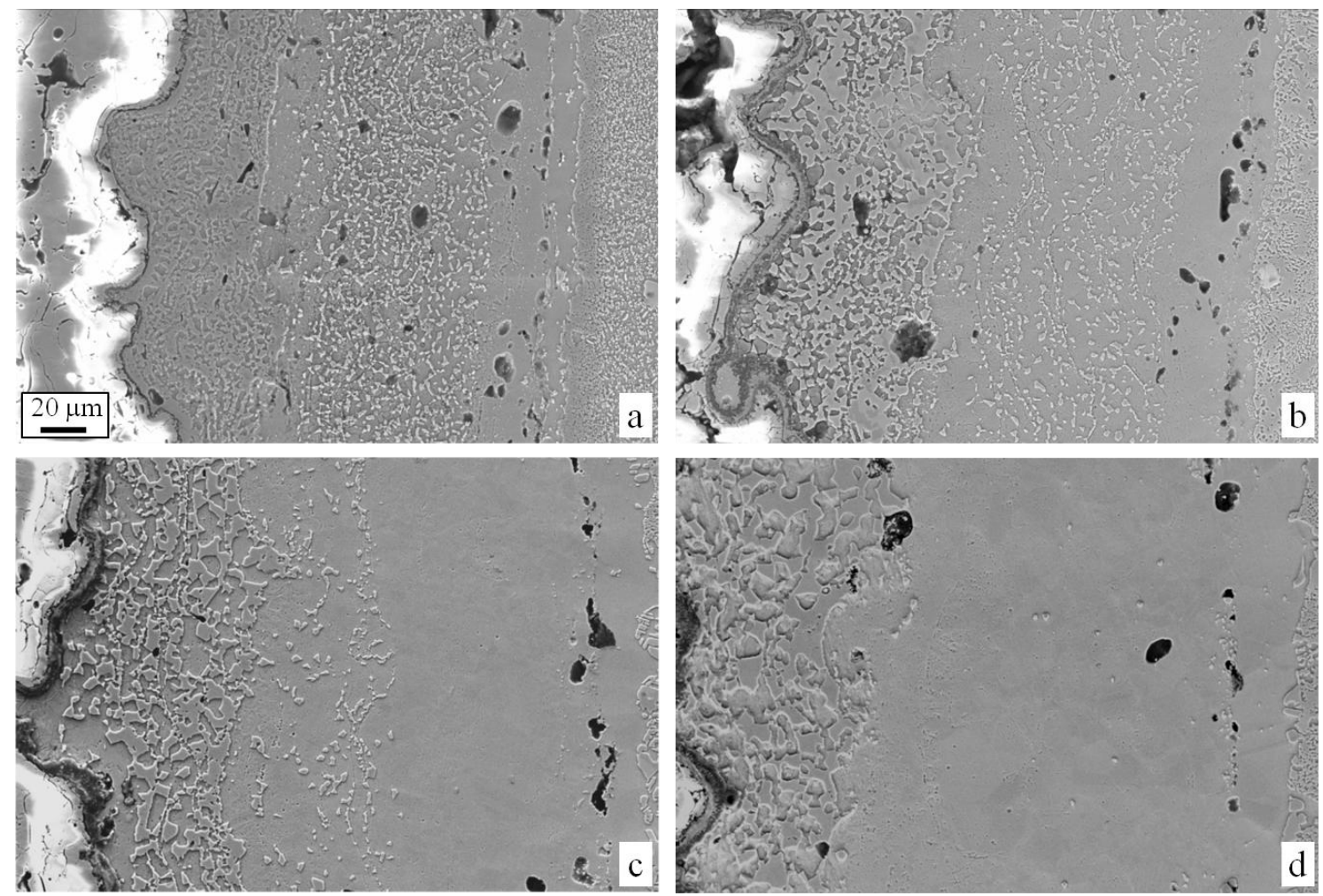

Figure 4. Secondary electron SEM images of (a) as-received (b) $100 \mathrm{~h}$ aged (c) $1000 \mathrm{~h}$ aged and (d) $3000 \mathrm{~h}$ aged samples all at $1000^{\circ} \mathrm{C}$, etched to remove a surface layer of the gamma phase, leaving the $\beta$ phase in relief.

In order to quantify the amount of the different phases within each layer, the samples were etched and imaged using secondary electron imaging in the FEGSEM. Figure 4 shows that the $\beta$ phase is easily distinguishable within both layers of the coating in the etched samples. It is revealed that the $\beta$ phase has different morphologies depending on whether the phase is in the outer layer or inner layer. The amount of $\beta$ in the inner layer reduces notably with ageing such that after $1000 \mathrm{~h}$, only a small amount of $\beta$ remains adjacent to the outer layer. After $3000 \mathrm{~h}$, no $\beta$ phase was observed in the inner layer. In the outer layer, $\beta$ phase coarsened during ageing, and the amount of $\beta$ phase also reduced. Figure 5 shows the quantified area percentage of $\beta$ throughout the coating. The profiles were produced through the use of image analysis techniques on the images displayed in Figure 4. The data have been smoothed using a 100 point $(25 \mu \mathrm{m})$ adjacent-averaging procedure (raw data are displayed in light grey). The Figure shows that in the outer layer, the amount of $\beta$ reduced with ageing time, but at a reduced rate when compared with the inner layer $\beta$ reduction. In summary, the $\beta$ phase coarsened and reduced in amount in the outer layer and became significantly depleted in the inner layer with ageing up to $3000 \mathrm{~h}$ at $1000^{\circ} \mathrm{C}$.



Figure 5. Profiles of the $\beta$ phase distribution within the coating produced through the use image analysis of the images displayed in Figure 4. The raw data (shown using a light grey narrow line for completeness) have been smoothed using a 100 point $(25 \mu \mathrm{m})$ adjacent-averaging procedure. The data between 0 and $25 \mu \mathrm{m}$ depth have been removed due to artefacts caused by the inconsistent position of the MCrAlY / TBC interface. 


\section{Discussion and Model Comparison}

Element diffusion analysis

The model prediction of the element diffusion profiles was initially compared with the experimental results obtained by the EDS matrix scanning technique. The results are given in Figure 6 (a) to (d) which shows the measured concentration distribution of $\mathrm{Al}$, Co and $\mathrm{Cr}$, alongside those predicted by the simulations for the AR, 100, 1000 and 3000h aged specimens. The AR condition was simulated using the PHT described earlier. In general, the model is able to reproduce the observed behaviour. As evident in Figure 6(a), in the case of the AR sample, a good agreement was found between the experimental and predicted profiles although the simulation slightly under-predicts the diffusion of Co within the inner layer. After 100h, in Figure 6(b), the model predictions generally correspond well with the measured values, although in the inner layer the predicted levels are marginally higher. In the case of Co, the overlap of the curves on either side of the inner layer is most noticeable. In the outer layer, the model slightly under-predicted the concentrations of $\mathrm{Al}$ and $\mathrm{Co}$, whilst overpredicting Cr. Across the inner layer of the samples, there is a gradual decrease in the measured Co level towards the outer layer, with a corresponding increase of $\mathrm{Co}$ in the outer layer when compared with the as received sample in Figure 6(a). This indicates that more Co has diffused into the outer layer across the boundary than predicted by the model. In the 1000 and $3000 \mathrm{~h}$ samples (Figure 6(c) \& (d)), the model prediction is fairly accurate for $\mathrm{Al}$ in the middle layer, especially after $3000 \mathrm{~h}$, but the sample seems to retain more $\mathrm{Al}$ in the outer layer than predicted by the simulation. The model prediction for $\mathrm{Co}$ and $\mathrm{Cr}$ deviates further from experimental observations. In the $1000 \mathrm{~h}$ aged sample, the model predicts a higher amount of Co being retained in the middle layer, which increases towards the centre compared to the fairly uniform levels measured experimentally. The model under-predicts the $\mathrm{Cr}$ concentrations in the inner layer while overpredicting them in the outer layer.

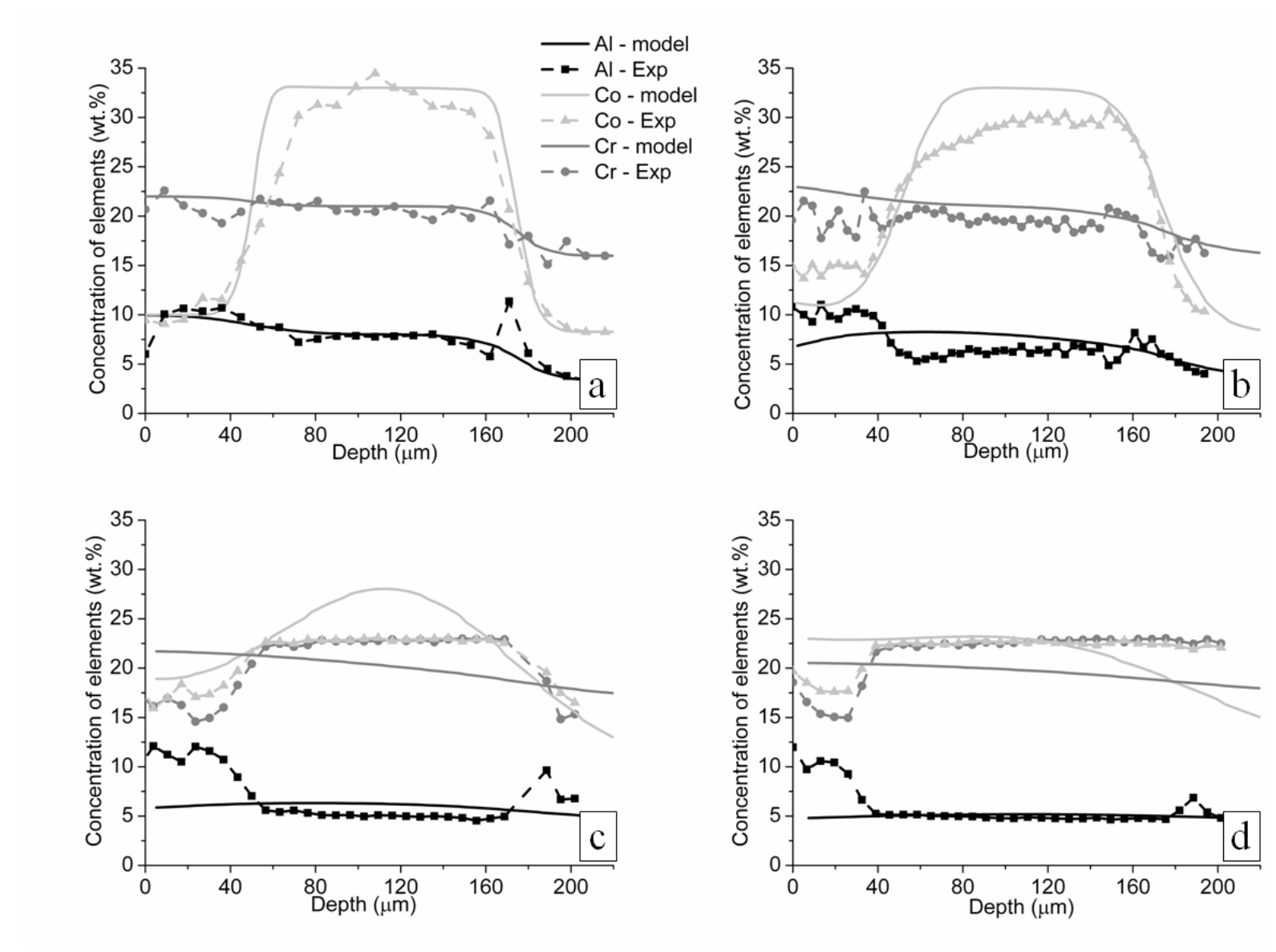

Figure 6. Elemental concentration profiles of $\mathrm{Al}$, $\mathrm{Co}$ and $\mathrm{Cr}$, measured in (a) as-received (AR), (b) 100h aged (c) 1000h aged and (d) $3000 \mathrm{~h}$ aged samples at $1000^{\circ} \mathrm{C}$, compared against the respective predictions from the diffusion model. 

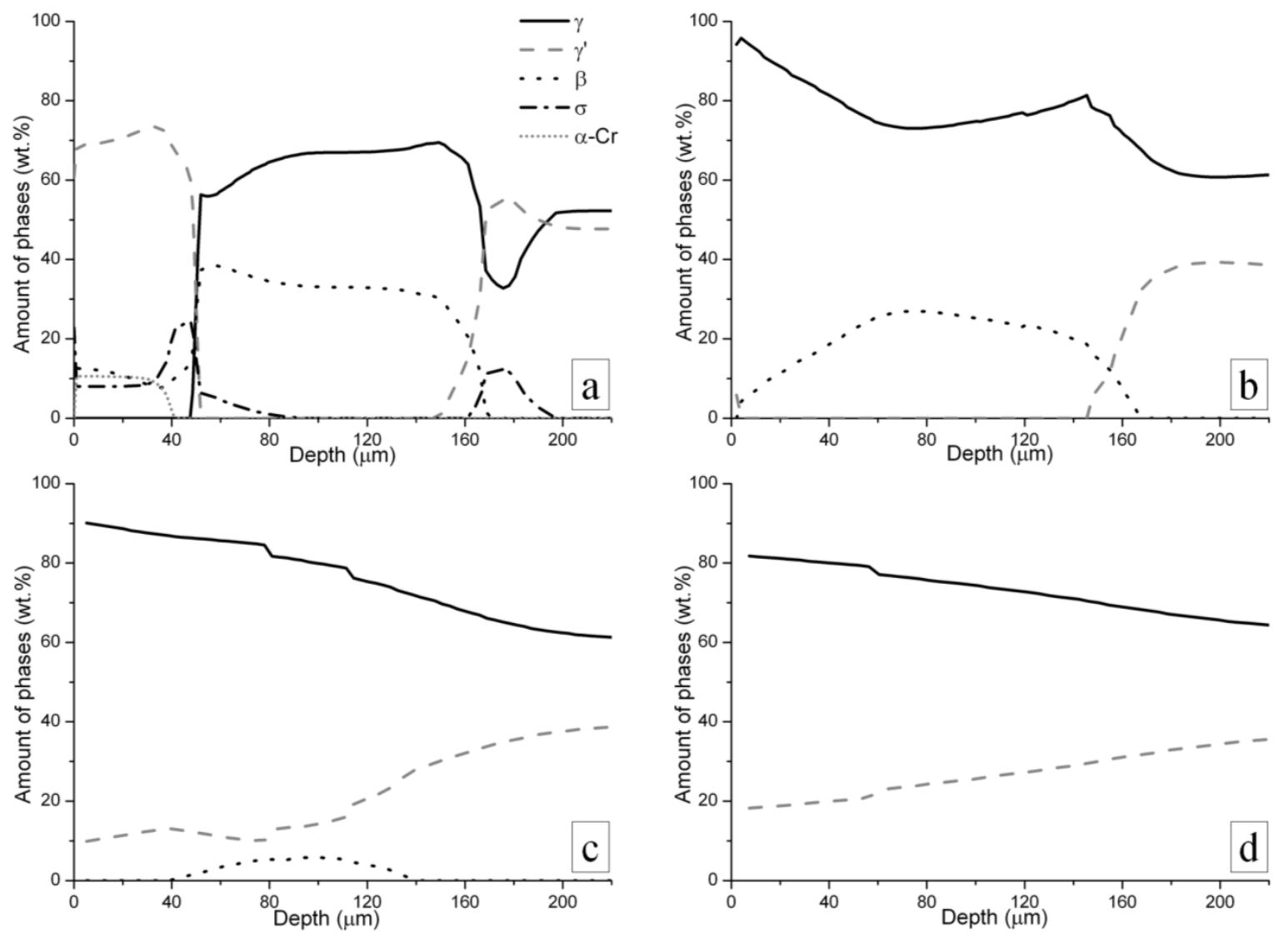

Figure 7. Simulation predictions of phase evolution profiles for the (a) as-received, (b) 100h aged, (c) 1000h aged, and (d) $3000 \mathrm{~h}$ samples aged at $1000^{\circ} \mathrm{C}$.

\section{Phase evolution}

A summary of the phase evolution predicted by the simulation model is presented in Figure 7 for the as received (AR), 100h, $1000 \mathrm{~h}$ and $3000 \mathrm{~h}$ aged samples at $1000^{\circ} \mathrm{C}$.

In the AR sample in Figure 7(a), the outer $\mathrm{NiCr}(\mathrm{Co}) \mathrm{AlY}$ layer is predicted to consist mainly of four phases: $\gamma^{\prime}, \beta, \alpha-\mathrm{Cr}$ and $\sigma$. In the inner layer, it is mainly $\gamma$ and $\beta$ with some sigma predicted near the interface between the coating layers. The phase structure across the coating system then quickly degenerates into a $\gamma+\beta$ configuration after just 100h (Figure 5(b)), with a thin layer of $\gamma^{\prime}$ predicted near the oxidation interface. After 1000h, in Figure 7(c), the $\beta$ phase has depleted almost entirely from the outer layer, and significantly from the inner layer and converted into $\gamma$ and $\gamma^{\prime}$. At $3000 \mathrm{~h}$ only a $\gamma+\gamma^{\prime}$ structure is predicted to be present, as shown in Figure 7(d).

These phase evolution predictions from the model can then be compared against the experimental observations which are depicted in micrographs shown in Figures 1, 4 and 5 and summarised in Table 3. In the as-received sample, the phases $\gamma^{\prime}$, $\beta$, and $\alpha-\mathrm{Cr}$ were clearly observed in the outer-layer of the experimental sample, and the presence of these phases is accurately predicted by the model output shown in Figure 7(a). The model however, also predicts the presence of the $\sigma$ phase in the outer and inner layers, increasing in quantity towards the inner / outer layer interface. This phase is however, not observable in these areas, and it is possible that $\sigma$ precipitation occurs after prolonged ageing. The inner layer consists mainly of $\gamma$ and $\gamma^{\prime}$ according to both model and experimental observations in Figure 1(a). The interdiffusion zone between the inner layer and substrate is marked by a thin layer of $\gamma^{\prime}$ and also the presence of $\gamma$ is noticeable in Figure 1(a). A phase with a bright appearance in the backscattered electron image can be identified as a TCP phase, most probably the $\sigma$ phase. All of these phases in the interdiffusion zone are accurately predicted by the model. After $100 \mathrm{~h}$, much of the $\gamma^{\prime}$ in the outer layer has transformed to $\gamma$, and the inner layer is composed of a $\gamma+\gamma^{\prime}$ structure. However, although the prediction by the model broadly agrees with the experimental observations, the $\alpha-\mathrm{Cr}$ phase observed in the outer layer and the $\sigma$ phase present in significant quantities in Figure 7(b), are not predicted by the model. The model predicts the $\beta$ depletion behaviour in the inner and outer coating well. For example, in Figure 4, the amount of the $\beta$ phase in the inner layer decreases with time and the phase is completely removed at 
$3000 \mathrm{~h}$, which is in complete agreement with model predictions in Figure 7. However, in the outer layer, a significant amount of $\beta$ phase still remains even after $3000 \mathrm{~h}$. This indicates the predicted $\beta$ depletion is slightly too fast. However, despite these minor differences, the model is able to predict successfully many features of phase evolution found in the experimental samples.

\section{Conclusions}

A comparison has been made between the element concentrations and phase evolution observed experimentally and those predicted by a multicomponent thermodynamic and kinetic model of a dual layered MCrAlY type coating system. It is demonstrated that there is both good qualitative and quantitative agreement between the predictions and observations. Dual layered MCrAlY coating systems have the potential to perform better than individual single layered coating systems, and this validated model is believed to be a useful design tool for the development of improved multilayered coating systems.

\section{Acknowledgements}

We would like to acknowledge the support of The Energy Programme, which is a Research Councils UK cross council initiative led by EPSRC and contributed to by ESRC, NERC, BBSRC and STFC, and specifically the Supergen initiative (Grants GR/S86334/01 and EP/F029748) and the following companies; Alstom Power Ltd., E.ON, Doosan Babcock, National Physical Laboratory, Praxair Surface Technologies, QinetiQ, Rolls-Royce plc, RWE npower, Siemens Industrial Turbomachinery Ltd. and Tata Steel for their valuable contributions to the project.

\section{References}

[1] J.R. Nicholls, N.J. Simms, W.Y. Chan, H.E. Evans, "Smart overlay coatings - concept and practice", Surface and Coatings Technology, 149 (2002), 236-244.

[2] W. Li, Y. Li, C. Sun, Z. Hu, T. Liang and W. Lai, "Microstructural characteristics and degradation mechanism of the NiCrAlY/CrN/DSM11 system during thermal exposure at $1100^{\circ} \mathrm{C} "$, J. Alloys Compounds, 506 (2010), 77-84.

[3] D. Monceau, D. Oquab, C. Estournes, M. Boidot, S. Selezneff, Y. Thebault, Y. Cadoret, "Pt-modified Ni aluminides, MCrAlY-base multilayer coatings and TBC systems fabricated by Spark Plasma Sintering for the protection of Nibase superalloys", Surface and Coatings Technology, 204 (2009), 771-778.

[4] M.S.A. Karunaratne, S.L. Ogden, S.D. Kenny, R.C. Thomson, "A multicomponent diffusion model for prediction of microstructural evolution in coated $\mathrm{Ni}$ based superalloy systems", Mater. Sci. Technology, 25 (2009), 287-299.

[5] A. Fick, "Ueber Diffusion", Annalen der Physik und Chemie, 94 (1855).

[6] L. Onsager, "Theories and Problems of Liquid Diffusion", Annals of New York Academy of Sciences, 46 (1945), 241-265.

[7] T. Ustad and H. Sorum, "Interdiffusion in the Fe-Ni, Ni-Co and Fe-Co Systems", Physica Status Solidi A: Applied Research, 20 (1973), 285-294.

[8] M.S.A. Karunaratne and R.C. Reed, "Interdiffusion of niobium and molybdenum in nickel between 900-1300 degrees C", Diffusion and Defect Data, 237-240 (2005), 420-425.

[9] N. Komai et al., "Analytical electron microscopy study of Ni/Ni-8 mol \% Ti diffusion couples", Acta Metallurgica, 46 (12) (1998), 4443-4451.

[10] M.S.A. Karunaratne, P. Carter and R.C. Reed, "Interdiffusion in the Face-Centred Cubic Phase of the NiRe, Ni-Ta and Ni-W Systems Between 900 and 1300 Celsius", Materials Science and Engineering, 281 (2000), 229-233.

[11] R.A. Swalin and R.A. Martin, "Solute Diffusion in Nickel Base Substitutional Solid Solutions", Transactions of the American Institute of Mining and Metallurgical Engineers, 1956, 567-572.

[12] A. Davin et al., "Comparison of the Diffusion of Some Substitution Elements in Nickel and Cobalt", Cobalt, 19 (1963), 51-56.

[13] T. Ikeda et al., "Interdiffusion in $\mathrm{Ni}_{3} \mathrm{Al}$ ", Diffusion and Defect Data. Part A: Defect and Diffusion Forum, 143-147 (1997), 275-278.

[14] St. Frank, U. Sodervall and C. Herzig, "Self- and Impurity Diffusion of $\mathrm{Ni}, \mathrm{Ga}, \mathrm{Ge}, \mathrm{Ti}, \mathrm{Nb}$ and $\mathrm{B}$ in the L12-type Intermetallic Compound $\mathrm{Ni}_{3} \mathrm{Al}^{\prime}$, Diffusion and Defect Data, 143-147 (1997), 245-250.

[15] Y. Minamino et al., "Diffusion of Cobalt, Chromium and Titanium in $\mathrm{Ni} / \mathrm{Ni}_{3} \mathrm{Al} "$ ", Metallurgical \& Materials Transactions A, 23A, (1992), 2783-2790.

[16] Wei, Hua, et al., "Estimation of interdiffusivity of the NiAl Phase in Ni-Al binary system", Acta Materialia, 52 (2004), 2645-2651.

[17] M.S.A. Karunaratne et al., "A multicomponent diffusion model for prediction of microstructural evolution in coated Ni-based superalloy systems", Materials Science and Technology, 25 (2) (2009), 287-299.

[18] S.M. Meier, D.M. Nissley and K.D. Sheffler, "Thermal Barrier Coating Life Prediction Model Development, \{Phase II Final Report\}", NASA Lewis Research Center, National Aeronautics and Space Administration, 1991, NASA Contractor Report. 18911/NAS3-23944.

[19] R.H. Davies, A.T. Dinsdale and J.A. Gisby, MTDATA Handbook: Application interface Programming Guide. National Physical Laboratory, Teddington, Middlesex TW11 0LW, UK, 1998.

[20] R.H. Davies et al., MTDATA -Thermodynamics and Phase Equilibrium Software from the National Physical Laboratory. CALPHAD, 26 (2) (2002), 229-271.

[21] N. Saunders, M. Fahrmann and C.J. Small, "The Application of CALPHAD Calculations to Ni-Based Superalloys". [ed.] T. M. Pollock, et al.: The Minerals, Metals \& Materials Society, Warrendale, PA 15086-7528, USA, 2000, Proceedings of the Ninth International Symposium on Superalloys, 803-811.

[22] N. Saunders, "Phase Diagram Calculations for Ni-based Superalloys", [ed.] R. D. Kissinger, et al.: The Minerals, Metals \& Materials Society, Warrendale, PA 15086-7528, USA, 1996, Proceedings of the Eighth International Symposium on Superalloys, 101-110.

[23] W.D. Murray and F. Landis, "Numerical and Machine Solutions of Transient Heat-Conduction Problems Involving Melting or Freezing Part I-Method of analysis and Sample Solutions", Transactions of the American Society of Mechanical Engineers, (81) (1959), 106-112. 